\title{
Incidence and impact of stroke following surgery for low-grade gliomas
}

\author{
*Assaf Berger, MD, Gali Tzarfati, BSc, Matias Costa, MD, Marga Serafimova, MD, \\ Akiva Korn, MMedSc, Irina Vendrov, MSc, Tali Alfasi, MA, Dana Krill, MA, Daniel Aviram, MD, \\ Shlomit Ben Moshe, MA, Alon Kashanian, BS, Zvi Ram, MD, and Rachel Grossman, MD

\begin{abstract}
Department of Neurosurgery, Tel-Aviv Medical Center, affiliated with the Sackler Faculty of Medicine, Tel-Aviv University, Tel-Aviv,
\end{abstract} \\ Israel
}

OBJECTIVE Ischemic complications are a common cause of neurological deficits following low-grade glioma (LGG) surgeries. In this study, the authors evaluated the incidence, risk factors, and long-term implications of intraoperative ischemic events.

METHODS The authors retrospectively evaluated patients who had undergone resection of an LGG between 2013 and 2017. Analysis included pre- and postoperative demographic, clinical, radiological, and anesthetic data, as well as intraoperative neurophysiology data, overall survival, and functional and neurocognitive outcomes.

RESULTS Among the 82 patients included in the study, postoperative diffusion-weighted imaging showed evidence of acute ischemic strokes in 19 patients (23\%), 13 of whom (68\%) developed new neurological deficits. Infarcts were more common in recurrent and insular surgeries $(p<0.05)$. Survival was similar between the patients with and without infarcts. Immediately after surgery, $27 \%$ of the patients without infarcts and $58 \%$ of those with infarcts experienced motor deficits $(p=0.024)$, decreasing to $16 \%(p=0.082)$ and $37 \%(p=0.024)$, respectively, at 1 year. Neurocognitive functions before and 3 months after surgery were generally stable for the two groups, with the exception of a decline in verbal rhyming ability among patients with infarcts. Confusion during awake craniotomy was a strong predictor of the occurrence of an ischemic stroke. Mean arterial pressure at the beginning of surgery was significantly lower in the infarct group.

CONCLUSIONS Recurrent surgeries and insular tumor locations are risk factors for intraoperative strokes. Although they do not affect survival, these strokes negatively affect patient activity and performance status, mainly during the first 3 postoperative months, with gradual functional improvement over 1 year. Several intraoperative parameters may suggest the impending development of an infarct.

https://thejns.org/doi/abs/10.3171/2019.10.JNS192301

KEYWORDS low-grade glioma; surgery; infarct; recovery; outcome; oncology

$\mathrm{M}$ AXIMAL resection of both high- and low-grade gliomas (LGGs) has been associated with better overall survival. ${ }^{8,23}$ However, acquired surgeryrelated neurological deficits can outweigh the benefit conferred by maximal resection and impair quality of life. Despite the aid of various intraoperative technologies, postoperative deficits are still a major concern, with a significant proportion of them resulting from ischemic complications. ${ }^{15,22}$ Reported rates of surgery-related ischemic strokes range from $21 \%$ to $80 \%$, and they were linked to new or worsened neurological deficits. ${ }^{16,22}$ Moreover, sur- gically acquired neurological deficits were associated with impaired quality of life and even decreased survival. ${ }^{19,31}$ The mixed populations with both high- and low-grade tumors in many studies have made it difficult to draw specific conclusions regarding strokes in LGG patients. Furthermore, most studies have not examined the long-term effects of these complications. ${ }^{9,15,31}$

In this study we aimed to evaluate the incidence of ischemic events and their risk factors in patients undergoing surgery for LGG, as well as the short- and long-term clinical and functional implications. We also searched for

ABBREVIATIONS DWI = diffusion-weighted imaging; EOR = extent of resection; IOM = intraoperative monitoring; KPS = Karnofsky Performance Status; LGG = low-grade glioma; MAP = mean arterial pressure; MEP = motor evoked potential; $m R S=$ modified Rankin Scale; Tc-MEP = transcortical MEP.

SUBMITTED August 22, 2019. ACCEPTED October 22, 2019.

INCLUDE WHEN CITING Published online December 27, 2019; DOI: 10.3171/2019.10.JNS192301.

${ }^{*}$ A.B. and G.T. share first authorship. 
intraoperative indicators of evolving strokes, adding to those in the currently available intraoperative monitoring (IOM) tool..$^{35}$

\section{Methods \\ Study Population}

We conducted a retrospective study to evaluate risk factors for surgical ischemic complications in patients who had undergone resection of LGG (WHO grade I or II) at our center between 2013 and 2017. We studied their intraoperative monitoring data and documented their shortand long-term implications. Patients who had undergone biopsy alone were excluded, as were those without full radiological and clinical data. The most recent operation was considered as the index surgery in patients who had undergone more than one surgery during the study period.

\section{Clinical and Demographic Data}

Admission, surgical, and discharge reports, including available documentation of follow-up in the ambulatory or hospital setting up to 1 year after surgery, were reviewed for each patient. The following parameters were documented: age; sex; body mass index; hand dominance; other malignancies; brain radiotherapy; cerebrovascular, cardiac, and metabolic comorbidities; and recurrent tumors. Data on any neurological manifestations, such as motor and speech deficits and seizures that had been observed before and immediately (within hours) after surgery and at 3, 6, and 12 months' follow-up, were documented when available. Based on each patient's functional capability in an affected limb, motor deficits were categorized into mild (weak but functional), moderate (partially functional with assistance), and severe (plegic or nonfunctional). Severity of speech deficits was categorized as mild (able to communicate independently), moderate (able to partially communicate with assistance), and severe (complete motor or sensory aphasia). Moreover, the Karnofsky Performance Status (KPS) and modified Rankin Scale (mRS) score were documented, and overall survival was calculated.

\section{Radiological Data}

We collected data on tumor volume and location, tumor enhancement, and extent of resection (EOR) calculated from preoperative and immediate postoperative MRI studies. The diagnosis of brain infarcts on immediate (within 48 hours) postoperative MRI was based on the presence of restrictive changes on diffusion-weighted imaging (DWI) and was differentiated from $\mathrm{T} 2$ shine-through and edema by the apparent diffusion coefficient technique. Infarcts were distinguished from restrictive changes of surgical retraction or blood products by their typical wedge-shaped arterial territory. Areas of T1-weighted hyperintensities were considered as blood products. ${ }^{44}$ The reports were provided by neuroradiologists blinded to clinical outcomes.

\section{Neurocognitive Analysis}

Patients were evaluated by neuropsychologists and completed a battery of computerized cognitive tests before surgery and at the 3-month follow-up. The NeuroTrax test- ing platform was used for assessment of various cognitive functions, including visual and verbal memory, executive function, attention, verbal function, and visual spatial processing. Previous validation studies have shown that NeuroTrax tests are comparable to traditional neuropsychological tests in their ability to differentiate cognitively healthy individuals from those with mild cognitive impairment. ${ }^{12}$ Test scores were calculated by software normalized for age and education level relative to a large normative database of healthy individuals and were fit to an IQ-style scale, with higher scores reflecting better performance (mean score 100, SD 15). Based on normalized test scores, the software generates index scores that summarize performance in particular cognitive domains. A global cognitive score computed as the average of theses index scores represents the overall cognitive performance. ${ }^{24}$ Alternate test forms provided by the software were used before and after surgery to minimize any learning effect. These tests have shown good test-retest reliability across testing sessions. ${ }^{12,43}$ Index scores and the global cognitive score were compared for each patient before and 3 months after surgery. The $p$ values were calculated to represent the significance of interaction between postsurgical changes in cognitive parameters and the occurrence of stroke. Table 1 lists the tests and cognitive domains that were assessed.

\section{Intraoperative Neurophysiological and Anesthetics Data}

Changes in transcranial, direct cortical, and subcortical motor evoked potentials (MEPs) on IOM were analyzed as reported previously by our team..$^{17,18,47}$ We used cortical and subcortical mapping in surgeries for lesions that involved or were close to the motor or visual pathways, as well as those in language function areas. Partial and complete declines in transcortical MEPs (Tc-MEPs) were reported, but not somatosensory evoked potentials. Navigation was used in all cases, and diffusion-tensor imaging for tractography was used in cases in which the lesion was proximal to motor and visual pathways, as well as language fasciculi. All awake craniotomy procedures were performed in the fully awake form. Monitoring during awake procedures was done by a trained neuropsychologist and included continuous physical examination for motor functions, as well as language assessments for the detection of semantic, phonemic, and expressive decline, comprehension, and confusion. Data on anesthetics included preoperative American Society of Anesthesiologists (ASA) classification, anesthesia duration, blood pressure measurements before and during surgery, and oxygen saturation. We compared patients anesthetized with total intravenous anesthesia (based on a combination of remifentanil [Ultiva, remifentanil $\mathrm{HCl}$, Abbott Laboratories] and propofol [Diprivan, AstraZeneca]) and those who additionally received gas anesthesia.

\section{Statistical Analysis}

Survival times were analyzed based on the KaplanMeier product limit method. Values are presented as the mean \pm standard deviation or standard error of the mean or the median and range, and a p value $<0.05$ (two-sided) was considered statistically significant. Characteristics be- 
TABLE 1. NeuroTrax tests used and cognitive domains assessed in this study

\begin{tabular}{|c|c|c|c|}
\hline Cognitive Domain & NeuroTrax Test & Test Description & Outcome Parameter \\
\hline \multirow[t]{2}{*}{ Memory } & $\begin{array}{l}\text { Verbal } \\
\text { Memory }\end{array}$ & $\begin{array}{l}10 \text { pairs of words are presented in } 4 \text { repetitions, each followed by a recognition } \\
\text { test in which } 1 \text { member of a previously presented pair appears together w/ a list } \\
\text { of } 4 \text { candidates for the other member of the pair; an additional recognition test } \\
\text { is administered after a delay }\end{array}$ & Accuracy, learning rate \\
\hline & $\begin{array}{l}\text { Nonverbal } \\
\text { Memory }\end{array}$ & $\begin{array}{l}8 \text { geometric objects are presented in } 4 \text { repetitions, each followed by a recogni- } \\
\text { tion test; participants are required to remember the orientations of the original } \\
\text { objects; an additional recognition test is administered after a delay }\end{array}$ & Accuracy, learning rate \\
\hline $\begin{array}{l}\text { Executive function } \\
\qquad \& \text { attention }\end{array}$ & Go-NoGo & $\begin{array}{l}\text { A series of colored stimuli are presented at pseudo-random intervals; participants } \\
\text { are instructed to respond as quickly as possible to all colors except red }\end{array}$ & $\begin{array}{l}\text { Accuracy, response time, } \\
\text { commission errors, } \\
\text { omission errors }\end{array}$ \\
\hline $\begin{array}{l}\text { Executive function } \\
\qquad \& \text { attention }\end{array}$ & Stroop & $\begin{array}{l}3 \text { phases: identify the color of common (non-color) words (e.g., "computer") shown } \\
\text { in colored letters; identify the meaning of color words (e.g., "blue") shown in } \\
\text { white letters; identify the color of color words when letter color \& word meaning } \\
\text { are conflicting (e.g., "blue" shown in red; correct response: red) }\end{array}$ & Accuracy, response time \\
\hline Verbal function & $\begin{array}{l}\text { Verbal Func- } \\
\text { tion }\end{array}$ & $\begin{array}{l}\text { Pictures of common objects are presented; participants are instructed to select } \\
\text { the word that best rhymes w/ the name of the object; in the matching phase, } \\
\text { participants are instructed to select the name of the object from } 4 \text { choices }\end{array}$ & Accuracy \\
\hline Visual spatial & $\begin{array}{l}\text { Visual Spatial } \\
\text { Processing }\end{array}$ & $\begin{array}{l}\text { Participants are instructed to imagine viewing a scene from the vantage point of a } \\
\text { red pillar \& choose from } 4 \text { alternative perspectives }\end{array}$ & Accuracy \\
\hline $\begin{array}{l}\text { Abstract reasoning/ } \\
\text { nonverbal IQ }\end{array}$ & $\begin{array}{l}\text { Problem Solv- } \\
\text { ing }\end{array}$ & $\begin{array}{l}\text { Pictorial puzzles of gradually increasing difficulty are presented; participants must } \\
\text { choose the element that best completes the matrix from } 6 \text { possible alternatives }\end{array}$ & Accuracy \\
\hline
\end{tabular}

tween groups and subgroups of categorical data were compared using Pearson's chi-square test and Fisher's exact test. Multivariate logistic regression analysis was used to evaluate risk factors for developing intraoperative stroke. Repetitively measured variables were analyzed using generalized estimating equations. Missing cases were not included in the analysis. Statistics were performed using SPSS 21.0 software (IBM Corp.). This study was approved by the institutional review board. Patient consent was not required given the retrospective nature of the study.

\section{Results \\ Clinical and Demographic Data}

Between 2013 and 2017, 120 patients underwent resection or biopsy for LGG at our center. We excluded cases that underwent biopsy for the diagnosis of LGG $(n=5)$, lacked pre- and postoperative MRI data $(n=4)$, or had no detailed reports on admission, surgery, and discharge (n $=29$ ). Full data sets, including long-term clinical evaluation findings, were available for 82 patients who had undergone resection, and they comprised our study cohort. Their mean age at surgery was $37 \pm 11$ years, and 53 patients $(65 \%)$ were males. Twenty-six patients $(32 \%)$ had surgery for recurrent tumor, and 37 procedures (45\%) were awake operations. Preoperative new-onset clinical manifestations included headache $(22 \%)$, motor deficits $(12 \%)$, speech deficits (13\%), and seizures (55\%). Sixteen percent of the patients had no new symptoms and were operated on for disease recurrence or progression seen on follow-up imaging. The median and range of preoperative KPS and mRS scores were $90(60-100)$ and $1(0-3)$, respectively. Forty-four resections (54\%) were performed on the right hemisphere. Tumor locations included frontal (33\%), tem- poral $(10 \%)$, parietal (13\%), and insular (34\%). The mean preoperative tumor volume was $39 \pm 31 \mathrm{ml}$, and the mean EOR was $88 \% \pm 12 \%$. All cases had pathological diagnoses of LGG according to the WHO classification. Twentytwo percent of the patients had oligodendrogliomas, and $72 \%$ were isocitrate dehydrogenase (IDH) mutated.

\section{Stroke Incidence and Risk Factors}

Immediate postoperative MRI studies showed evidence of an acute ischemic stroke adjacent to the tumor resection cavity in 19 patients (23\%), and $13(68 \%)$ of them developed new neurological deficits resulting from the ischemic event. Comparisons between the study groups in a univariate analysis are featured in Table 2. Infarcts were more common in patients undergoing surgery for a recurrent tumor and especially in those with tumors involving the insula ( $\mathrm{p}<0.05)$. Most insular tumors $(19$ [68\%]) were resected transcortically, while $9(32 \%)$ were removed via the transsylvian approach. The transcortical approach was used in 10 stroke cases (53\%) and 9 nonstroke cases $(14 \% ; \mathrm{p}=0.885)$. Preoperative tumor size was higher in the infarct group, but not statistically significantly so ( $p$ $=0.052$ ). On the other hand, contrast enhancement and a frontal location were associated with a lower risk of stroke in a univariate analysis $(\mathrm{p}<0.05)$. After a multivariate analysis for potential confounders that came up in the univariate calculations, surgery for insular gliomas had the strongest association with postoperative infarcts (OR 12.4, 95\% CI 2.21-69.8), while enhancing tumors had a significantly lower rate of infarcts (Table 3 ). We had very few patients with other comorbidities, and we did not detect any association between them and surgery-related stroke $(p>0.05)$. Most of the strokes (14/19 [74\%]) involved the 
TABLE 2. Clinical and demographic data of patients with and without surgery-related brain infarcts

\begin{tabular}{lccc}
\hline \multicolumn{1}{c}{ Variable } & No Infarct & Infarct & p Value \\
\hline No. of patients & $63(77 \%)$ & $19(23 \%)$ & \\
\hline Age in yrs & $37 \pm 12$ & $36 \pm 10$ & 0.678 \\
\hline Male sex & $64 \%$ & $68 \%$ & 0.789 \\
\hline BMl in kg/m ${ }^{2}$ & $25.0 \pm 4.3$ & $23.59 \pm 4.4$ & 0.252 \\
\hline Preop KPS $\geq 70$ & $100 \%$ & $95 \%$ & 0.232 \\
\hline Preop mRS score $\leq 3$ & $100 \%$ & $100 \%$ & \\
\hline Ever smoking & $18 \%$ & $11 \%$ & 0.722 \\
\hline Preop serum Hb in g/dl & $13.8 \pm 1.4$ & $13.5 \pm 1.5$ & 0.417 \\
\hline Recurrent tumor & $25 \%$ & $52 \%$ & 0.046 \\
\hline Previous radiation & $8 \%$ & $11 \%$ & 0.648 \\
\hline Awake procedure & $48 \%$ & $37 \%$ & 0.443 \\
\hline Tumor enhancement & $44 \%$ & $11 \%$ & 0.012 \\
\hline Preop tumor vol in $\mathrm{ml}$ & $35 \pm 32$ & $52 \pm 34$ & 0.052 \\
\hline EOR & $89 \% \pm 11 \%$ & $87 \% \pm 13 \%$ & 0.681 \\
\hline Ki-67 $\geq 5 \%$ & $21 \%$ & $17 \%$ & 0.99 \\
\hline IDH1+ & $70 \%$ & $79 \%$ & 0.566 \\
\hline Tumor location & & & \\
\hline Frontal & $40 \%$ & $11 \%$ & 0.024 \\
\hline Insular & $21 \%$ & $79 \%$ & 0.001 \\
\hline Temporal & $11 \%$ & $5 \%$ & 0.674 \\
\hline Parietal & $18 \%$ & 0 & 0.06 \\
\hline BM = body mas & & & \\
\hline
\end{tabular}

$\mathrm{BMI}=$ body mass index; $\mathrm{Hb}=$ hemoglobin; IDH1 = isocitrate dehydrogenase 1 . Values are expressed as the mean \pm standard deviation or as percentage, unless indicated otherwise. Boldface type indicates statistical significance.

middle cerebral artery territory, whereas 5 (26\%) involved the anterior cerebral artery. Mean infarct volume was 14 $\mathrm{ml}$ (range 2-27 ml). The following locations were involved by stroke: frontal, 9 (47\%); insular, 6 (32\%); parietal, 1 (5\%); temporal, 5 (26\%); internal capsule, $9(47 \%)$; caudate nucleus, 9 (47\%); other basal ganglia, 3 (16\%); thalamus, $2(11 \%)$; Wernicke's area and superior longitudinal fasciculus, 2 (11\%); and optic radiation, 2 (11\%). Interestingly, temporal strokes occurred only $(100 \%)$ in recurrent cases; none occurred in first-time surgeries $(\mathrm{p}=0.033)$. We did not detect any significant differences in comparing other stroke locations in recurrent and first-time surgeries $(\mathrm{p}>$ $0.05)$.

TABLE 3. Multivariate logistic regression analysis for estimating risk factors for intraoperative stroke

\begin{tabular}{lcc}
\hline \multicolumn{1}{c}{ Risk } & OR $(95 \% \mathrm{Cl})$ & p Value \\
\hline Insular lesion & $12.4(2.21-69.8)$ & $\mathbf{0 . 0 0 4}$ \\
\hline Recurrent tumor & $4.72(1.13-19.67)$ & $\mathbf{0 . 0 3 3}$ \\
\hline Protective & & \\
\hline Frontal lesion & $0.89(0.11-7.54)$ & 0.917 \\
\hline Contrast enhancement & $0.14(0.02-0.91)$ & $\mathbf{0 . 0 4}$ \\
\hline
\end{tabular}

Boldface type indicates statistical significance.

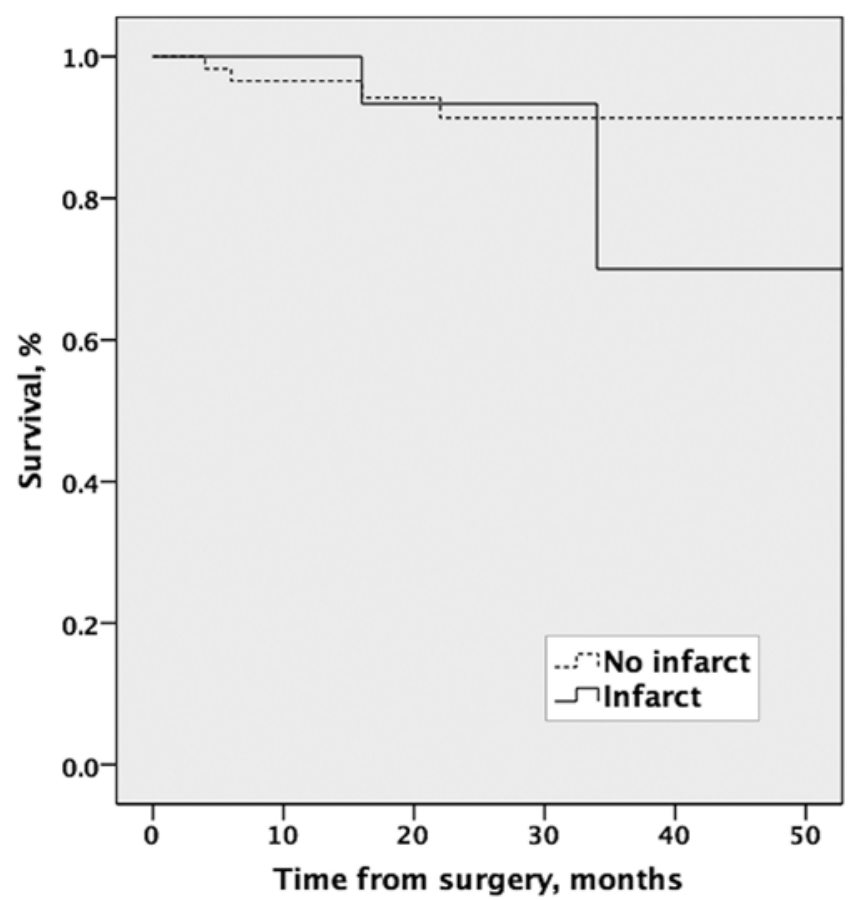

FIG. 1. Kaplan-Meyer survival curves of patients with and without intraoperative infarcts $(p=0.187$, log-rank test).

\section{Clinical, Functional, and Cognitive Outcomes}

Patients were followed up for a mean period of $26 \pm$ 16 months after surgery. There were 7 deaths during the follow-up period, with none of the deaths related to surgery, and mean overall survival was 54 months (95\% CI 51-58 months). There was no difference in survival between the study groups ( $p=0.187$; Fig. 1 ). Median KPS was lower in the infarct group at 3 months after surgery $(\mathrm{p}=0.039)$, with gradual significant improvement over 1 year of follow-up ( $p=0.041)$. Furthermore, the median $\mathrm{mRS}$ score in the infarct group was higher than that in the noninfarct group at 3 months after surgery $(2[0-4]$ and $1[0-3]$, respectively, $\mathrm{p}=0.027)$; a nonsignificant improvement was noted at 1 year $(\mathrm{p}=0.074)$. Immediately after surgery, $27 \%$ of patients without infarct and $58 \%$ of those with infarct experienced motor deficits $(\mathrm{p}=0.024)$, which decreased to $16 \%(\mathrm{p}=0.082)$ and $37 \%(\mathrm{p}=0.024)$, respectively, at 1 year. Four of the patients with infarcts $(21 \%)$ had severe motor deficits (as opposed to $2 \%$ in the noninfarct group, $\mathrm{p}=0.014$ ). This rate went down to $5 \%$ at 1 year after surgery $(p=0.06)$. Speech deficits were observed in $3(43 \%)$ of the 7 patients who sustained infarcts following dominant-side surgery, and this rate persisted until 1 year. Only 1 patient had a severely disabling deficit after surgery, which improved with time. However, we did not detect significant differences in the rate of speech deficits between patients with and those without stroke after dominant-side surgery because of the small size of that subgroup $(n=40)$. Neither did we find any differences in the rate of postoperative seizures between patients with and without stroke (Table 4). Stable results were shown among the 33 patients who had undergone neurocognitive 
TABLE 4. Clinical outcomes in 82 LGG patients with and without surgery-related infarcts

\begin{tabular}{|c|c|c|c|c|c|c|c|c|c|c|}
\hline \multirow[b]{2}{*}{ Variable } & \multicolumn{2}{|c|}{ KPS } & \multicolumn{2}{|c|}{ mRS Score } & \multicolumn{2}{|c|}{ Motor Deficit (\%) } & \multicolumn{2}{|c|}{ Seizures (\%) } & \multicolumn{2}{|c|}{ Speech Deficit (\%)* } \\
\hline & No Infarct & Infarct & No Infarct & Infarct & No Infarct & Infarct & No Infarct & Infarct & No Infarct & Infarct \\
\hline Preop & $90(70-100)$ & $90(60-100)$ & $1(0-3)$ & $1(0-3)$ & 17 & 16 & 59 & 63 & 30 & 14 \\
\hline Immediate postop & - & - & - & - & 27 & 58 & 64 & 74 & 33 & 43 \\
\hline 3 mos postop & $90(60-100)$ & $80(40-100)$ & $1(0-3)$ & $2(0-4)$ & 29 & 47 & 65 & 74 & 33 & 43 \\
\hline 6 mos postop & $90(70-100)$ & $90(40-100)$ & $1(0-5)$ & $2(0-4)$ & 14 & 42 & 33 & 26 & 21 & 43 \\
\hline 12 mos postop & $90(60-100)$ & $90(50-100)$ & $1(0-3)$ & $1(0-4)$ & 16 & 37 & 59 & 63 & 21 & 43 \\
\hline p value $†$ & \multicolumn{2}{|c|}{0.018} & \multicolumn{2}{|c|}{0.013} & \multicolumn{2}{|c|}{0.033} & \multicolumn{2}{|c|}{0.695} & \multicolumn{2}{|c|}{0.292} \\
\hline
\end{tabular}

Values expressed as median (range) or as percentage, unless indicated otherwise. Boldface type indicates statistical significance.

* Speech deficit analysis was performed in a subgroup of dominant-side surgeries $(n=40)$, comparing infarct $(n=7)$ and noninfarct $(n=33)$ groups.

† Multivariate analysis for comparing infarct and noninfarct groups adjusted for insular and frontal lesions, recurrent tumors, and contrast enhancement.

analyses before and 3 months after surgery, except for a significant decrease in rhyming in the verbal function domain among patients with infarcts (Table 5).

\section{Intraoperative Monitoring of Stroke}

Intraoperative neurophysiology data were available in 50/82 cases. Fifteen cases (30\%) showed decline in MEPs; $5(10 \%)$ were complete and $10(20 \%)$ were partial. In general, 6 patients (38\%) with MEP decline had evidence of infarcts on postoperative MRI, as compared with 9 patients $(26 \%)$ without decline $(\mathrm{p}=0.514)$. No significant differences were detected when comparing cases with either complete or partial decline and those with no decline in MEPs ( $\mathrm{p}=0.307$ and $\mathrm{p}=1.0$, respectively). In general, a decline in MEPs was associated with new postoperative motor deficits in 53\% of cases, as compared with $37 \%$ of cases when no MEP decline was reported $(\mathrm{p}=0.356)$. Among the monitored patients without infarcts $(\mathrm{n}=34)$, MEP decline occurred in 9 patients (26\%) and was linked to new postoperative motor deficits in 4 patients (44\%); the new deficits remained permanent in only 1 of these patients. In contrast, 6/25 patients (24\%) without MEP decline showed new postoperative motor deficits, which remained permanent in 2 patients (Table 6).

According to intraoperative neuropsychological monitoring findings in awake surgeries, confusion and motor decline on physical examination were significantly more common among patients with infarcts ( $\mathrm{p}<0.05$; Table 6). According to anesthesiology charts, patients with infarcts, as compared to those without, had a significantly lower baseline mean arterial pressure (MAP) at the beginning of surgery $(79 \pm 14$ and $92 \pm 16 \mathrm{~mm} \mathrm{Hg}$, respectively, $\mathrm{p}=$ 0.028 ). Univariate analysis revealed a significantly longer duration of anesthesia ( $429 \pm 26$ minutes) among patients who had surgery-related infarcts than that among patients with no infarcts $(334 \pm 11$ minutes; $p=0.002)$. This difference was not significant in the multivariate analysis ( $p$ $=0.077$ ). Total intravenous anesthesia was induced in 40 cases (49\%), with no significant differences between the study groups $(\mathrm{p}=0.746)$.

\section{Discussion}

To the best of our knowledge, this is the first study to describe the incidence and characteristics of intraoperative ischemic complications and the long-term outcome in patients undergoing surgery for LGG.

\section{Stroke Incidence and Risk Factors}

According to immediate postoperative MRI findings, $23 \%$ of our patients were diagnosed with surgery-related brain infarcts. This incidence is in line with previously published rates. ${ }^{16}$ Similar to earlier reports, ${ }^{11,15}$ our study showed that recurrent tumors were associated with ischemic complications and that patients with recurrent tumors had a nearly fivefold higher risk for intraoperative stroke than patients with newly diagnosed tumors (multivariate regression analysis, $\mathrm{p}<0.05$ ). However, an insular tumor location was the strongest risk factor for the development of intraoperative ischemia, comprising $79 \%$ of all cases with infarcts (Tables 2 and 3). Insular tumors are notorious for their risk for surgical morbidity given their proximity to critically eloquent landmarks and complex vascular anatomy. In contrast to other locations, the insula is largely and frequently supplied by perforating arteries with no collateral flow. Various mechanisms have been proposed for the development of intraoperative brain ischemia, including direct vascular damage and coagulation, vasospasm, and kinking of arteries by the retraction of the brain that is often required in insular surgeries. ${ }^{11,16 \text {, }}$ $34,35,38$ Whether the transsylvian approach to insular tumors, as compared with the transcortical approach, poses a higher risk for vascular complications and morbidity is still controversial, and different views are mainly based on personal experience. ${ }^{20,37,39}$ Our study showed no differences between the approach groups in terms of intraoperative stroke. Given our experience, we tend to believe that most infarcts do not result from direct vascular damage, but rather from surgical manipulation, which Penfield et al. termed "manipulation hemiplegia." ${ }^{36}$ Previous studies have shown that preoperative diagnostic angiography and potentially MRI-based angiography can identify lenticulostriate arteries that are encased by the tumor and therefore predict the risk for ischemic complications. ${ }^{6,25,32}$ Whether these tools are required for surgical planning should be further studied, especially in high-risk cases such as insular tumors. Interestingly, contrast-enhancing lesions had a significantly lower risk for intraoperative stroke than 
TABLE 5. Cognitive functions in patients with and without infarcts before and 3 months after surgery

\begin{tabular}{|c|c|c|c|}
\hline Cognitive Function & $\begin{array}{c}\text { No Infarct } \\
(n=24)\end{array}$ & $\begin{array}{l}\text { Infarct } \\
(n=9)\end{array}$ & $p$ Value \\
\hline \multicolumn{4}{|l|}{ Global cognitive score } \\
\hline Preop & $96 \pm 8$ & $92 \pm 12$ & \multirow{2}{*}{0.434} \\
\hline Postop & $96 \pm 8$ & $89 \pm 11$ & \\
\hline \multicolumn{4}{|l|}{ Domain index scores } \\
\hline \multicolumn{4}{|l|}{ Memory } \\
\hline Preop & $91 \pm 15$ & $89 \pm 16$ & \multirow{2}{*}{0.493} \\
\hline Postop & $94 \pm 12$ & $92 \pm 13$ & \\
\hline \multicolumn{4}{|l|}{ Executive function } \\
\hline Preop & $93 \pm 12$ & $92 \pm 17$ & \multirow{2}{*}{0.522} \\
\hline Postop & $95 \pm 13$ & $86 \pm 15$ & \\
\hline \multicolumn{4}{|l|}{ Attention } \\
\hline Preop & $91 \pm 13$ & $88 \pm 21$ & \multirow{2}{*}{0.355} \\
\hline Postop & $89 \pm 19$ & $83 \pm 19$ & \\
\hline \multicolumn{4}{|l|}{ Visual spatial } \\
\hline Preop & $104 \pm 13$ & $95 \pm 15$ & \multirow{2}{*}{0.217} \\
\hline Postop & $104 \pm 12$ & $101 \pm 12$ & \\
\hline \multicolumn{4}{|l|}{ Verbal function } \\
\hline Preop & $103 \pm 8$ & $100 \pm 9$ & \multirow{2}{*}{0.041} \\
\hline Postop & $100 \pm 10$ & $83 \pm 19$ & \\
\hline \multicolumn{4}{|l|}{ Individual test scores } \\
\hline \multicolumn{4}{|l|}{ Immediate verbal memory } \\
\hline Preop & $86 \pm 23$ & $70 \pm 38$ & \multirow{2}{*}{0.452} \\
\hline Postop & $94 \pm 18$ & $92 \pm 24$ & \\
\hline \multicolumn{4}{|l|}{ Problem solving } \\
\hline Preop & $94 \pm 17$ & $100 \pm 11$ & \multirow{2}{*}{0.317} \\
\hline Postop & $88 \pm 17$ & $79 \pm 8$ & \\
\hline \multicolumn{4}{|l|}{ Stroop } \\
\hline Preop & $92 \pm 13$ & $87 \pm 14$ & \multirow{2}{*}{0.955} \\
\hline Postop & $97 \pm 15$ & $87 \pm 14$ & \\
\hline \multicolumn{4}{|l|}{ Delayed verbal memory } \\
\hline Preop & $86 \pm 22$ & $91 \pm 16$ & \multirow{2}{*}{0.630} \\
\hline Postop & $95 \pm 20$ & $104 \pm 8$ & \\
\hline \multicolumn{4}{|c|}{ Immediate nonverbal memory } \\
\hline Preop & $93 \pm 19$ & $95 \pm 18$ & \multirow{2}{*}{0.840} \\
\hline Postop & $90 \pm 20$ & $86 \pm 24$ & \\
\hline \multicolumn{4}{|c|}{ Delayed nonverbal memory } \\
\hline Preop & $97 \pm 19$ & $100 \pm 11$ & \multirow{2}{*}{0.529} \\
\hline Postop & $95 \pm 21$ & $86 \pm 29$ & \\
\hline
\end{tabular}

$\mathrm{n}=$ number of patients.

All scores were normalized for age and educational level and fit to an IQ-style scale (mean score 100, SD 15; see Methods). Multivariate analysis for insular and frontal lesions, recurrent tumors, and contrast enhancement. The $p$ values relate to the significance of interaction between postsurgical changes in cognitive parameters and the occurrence of stroke. Boldface type indicates statistical significance.
TABLE 6. Indicators of intraoperative stroke via IOM, awake surgery monitoring, and anesthesiology parameters

\begin{tabular}{|c|c|c|c|}
\hline Indicator & No Infarct & Infarct & $\mathrm{p}$ Value \\
\hline \multicolumn{4}{|l|}{ IOM } \\
\hline No. of patients $(n=50)$ & 34 & 16 & \\
\hline MEPs decline, $\%$ of patients & $26 \%$ & $38 \%$ & 0.514 \\
\hline \multicolumn{4}{|l|}{ Awake monitoring } \\
\hline No. of patients $(n=34)$ & 27 & 7 & \\
\hline Seizure, $\%$ of patients & $11 \%$ & $14 \%$ & 0.469 \\
\hline $\begin{array}{l}\text { Intraop motor decline, } \% \text { of } \\
\text { patients }\end{array}$ & $8 \%$ & $43 \%$ & 0.006 \\
\hline $\begin{array}{l}\text { Intraop semantic decline, \% of } \\
\text { patients }\end{array}$ & $21 \%$ & $0 \%$ & 0.545 \\
\hline $\begin{array}{l}\text { Intraop production decline, \% } \\
\text { of patients }\end{array}$ & $19 \%$ & $14 \%$ & 0.883 \\
\hline $\begin{array}{l}\text { Comprehension difficulties, \% } \\
\text { of patients }\end{array}$ & 0 & 0 & \\
\hline Confusion, $\%$ of patients & 0 & $29 \%$ & 0.023 \\
\hline Exhaustion, $\%$ of patients & $27 \%$ & $57 \%$ & 0.383 \\
\hline \multicolumn{4}{|l|}{ Anesthesiology parameters } \\
\hline No. of patients $(n=82)$ & 63 & 19 & \\
\hline ASA class $\geq 111, \%$ of patients & $22 \%$ & $5 \%$ & 0.407 \\
\hline TIVA, $\%$ of patients & $48 \%$ & $53 \%$ & 0.746 \\
\hline Anesthesia time in mins & $334 \pm 11$ & $429 \pm 26$ & 0.077 \\
\hline Time MAP $<65 \mathrm{~mm} \mathrm{Hg}$ in mins & $34 \pm 6$ & $71 \pm 18$ & 0.110 \\
\hline $\begin{array}{l}\text { MAP }<65 \mathrm{~mm} \mathrm{Hg} / \mathrm{anesthesia} \\
\text { time, } \%\end{array}$ & $10 \pm 2$ & $16 \pm 4$ & 0.939 \\
\hline Baseline MAP in mm Hg & $92 \pm 16$ & $79 \pm 14$ & 0.028 \\
\hline Min MAP in mm Hg & $56 \pm 10$ & $54 \pm 9$ & 0.899 \\
\hline Min MAP/baseline MAP, \% & $37 \pm 14$ & $29 \pm 15$ & 0.062 \\
\hline $\operatorname{Min} \mathrm{O}_{2}, \%$ & $96 \pm 2.8$ & $95.7 \pm 2.7$ & 0.893 \\
\hline
\end{tabular}

ASA = American Society of Anesthesiologists; $n=$ number of patients; TIVA $=$ total intravenous anesthesia.

Values are expressed as the number, percentage, or mean \pm standard error of the mean, unless indicated otherwise. Multivariate analysis for infarct versus no infarct adjusted for insular and frontal lesions, recurrent tumors, and contrast enhancement. Boldface type indicates statistical significance.

nonenhancing lesions (Tables 2 and 3). We assume that contrast enhancement indicates a less firm tumor texture, which facilitates its resection and requires less manipulation of normal brain parenchyma. However, no data supporting such a hypothesis are available. Another interesting finding was a substantially higher rate of temporal strokes in recurrent cases, as compared with first-time surgeries. We have no clear explanation, but dural adherence, proximity to the sylvian fissure, scarring, and decreased mobility of the arterial supply to this specific location are all potential reasons for this change in stroke risk patterns in recurrent surgeries.

\section{Clinical, Functional, and Cognitive Outcomes}

Thirteen $(68 \%)$ of the 19 patients with infarcts on postoperative imaging had new neurological deficits and were 
considered to have sustained symptomatic infarcts. Intraoperative peritumoral infarcts, as detected by immediate postoperative DWI, are more commonly seen among glioma patients with surgically acquired deficits, mainly in the form of motor or speech deficits. ${ }^{15,22}$ In general, as was recently described, postoperative deficits occur transiently in $17 \%$ of newly diagnosed glioma cases and are permanent in $7 \% .{ }^{15}$ To our knowledge, however, none of these studies has followed the long-term dynamics of these deficits. In the current cohort, motor deficits were significantly more common among patients with intraoperative stroke throughout the 1 year of follow-up. However, there was also significant improvement in the rate and severity of deficits during the 1st year after surgery. While $58 \%$ of patients with an infarct experienced motor deficits immediately after surgery, only $37 \%$ of them retained those deficits at 1 year $(\mathrm{p}=0.024)$. Because of the small size of the subgroup, we were unable to detect a significantly higher rate of gross speech deficits among patients who had undergone dominant-side surgery and had sustained strokes than that among controls (Table 4).

The question of whether intraoperative strokes increase the rate of seizures is often discussed. Our study results showed no statistically significant difference between patients with and without strokes and reaffirm the general notion of previous reports about having weak evidence for recommending prophylactic administration of antiepileptic drugs based on the diagnosis of surgery-related infarcts. ${ }^{10,22}$

Moreover, we followed two functional assessment scores, the KPS (oncological) and mRS score (stroke), which complete each other in characterizing the competence of our unique population of cancer patients with stroke-related neurological deficits. ${ }^{1,42}$ Interestingly, patients with infarcts had a significantly lower KPS than the noninfarct group at 3 months after surgery, with significant improvement over 1 year of follow-up. In parallel, the $\mathrm{mRS}$ score in patients with infarcts was higher than that in those without infarcts at 3 months after surgery and gradually improved over 1 year, signifying general functional improvement in surgical vascular complications (Table 4).

Glioma patients often sustain various forms of preoperative cognitive impairments that can further deteriorate after surgery, depending on the eloquence of the tumor location. We evaluated the neurocognitive functions of LGG patients with intraoperative stroke since cognitive functions commonly improve when analyzed up to 1 year after surgery. ${ }^{40,41}$ The results of NeuroTrax computerized testing before and 3 months after surgery were relatively similar between the infarct and no-infarct groups, except for a significant decrease in rhyming ability among the infarct patients (Table 5). These results are in accordance with functional MRI findings of associations between verbal fluency/rhyming ability and perisylvian and insular areas, ${ }^{28}$ which were more commonly affected by strokes in the current and previous reports..$^{11,34}$ Interestingly, another recent study showed a slight decline in semantic fluency in patients with small infarcts following glioma surgery involving insulo-opercular areas. ${ }^{27}$ However, as only 33 of our patients had a neurocognitive evaluation, we could not perform a subgroup analysis for surgeries in the dominant hemisphere, which may have revealed further cognitive sequelae.

\section{Intraoperative Indicators of Stroke}

Intraoperative detection of impending stroke or stroke in evolution has been the target of several research teams since a prompt response can improve the chances of limiting declines to transient instead of permanent deficits. Although intraoperative MRI was efficient in estimating $\mathrm{EOR}$, its role in detecting surgery-related ischemic lesions is doubted..$^{30}$ The monitoring of intraoperative MEPs could reveal early ischemia and even prevent it from becoming permanent through the implementation of a therapeutic response, such as holding surgery, irrigating with saline and locally administering papaverine, and releasing retraction on the brain parenchyma. ${ }^{16,34,35}$ Our current research did not show significant associations between these studied parameters, possibly due to the fact that the motor pathways were involved in only part of the strokes. Therefore, a larger cohort may have revealed the feasibility of detecting impending stroke via IOM. Interestingly though, 27\% of monitored patients without infarcts had MEP decline, which was linked to new postoperative motor deficits in $44 \%$ of these cases. Possible explanations for these events include direct mechanical injury to the motor pathway during resection in a minority of cases, as well as indirect damage by local traction and transient edema along the motor fibers. ${ }^{16}$ The second explanation is probably more common and explains the transiency of the majority of these new postoperative deficits in the current study. ${ }^{16,34}$ False-positive cases, in which IOM abnormality was noted without postoperative deficits, can result from intraoperative interventions such as adjusting retraction, raising blood pressure, or halting surgery. ${ }^{33-35}$ On the other hand, false-negative cases, in which new postoperative motor deficits were noted without warning signs of IOM abnormalities, can be explained in part by a "bypass" mechanism in which Tc-MEPs reach the motor pathways beyond the point of operation. ${ }^{33,45}$ Transient postoperative motor deficits can also be explained by the late development of local edema around the pyramidal tracts or by resections involving the supplementary motor area, which are known to improve with time and do not manifest with IOM abnormalities. ${ }^{2,13,33,45}$

Language mapping is a common modality for guiding resection near eloquent areas in awake operations. ${ }^{26}$ Among the tested parameters, intraoperative confusion was associated with the occurrence of infarcts on postoperative MRI and thus may be considered as a possible indicator of the development of stroke in awake procedures (Table 6).

Among the intraoperative anesthesiology parameters, an MAP reduction of 20\%-30\% below baseline has been associated with a higher risk for postoperative stroke. ${ }^{7,29,46}$ We found that patients who developed intraoperative stroke had a significantly lower MAP at the beginning of surgery. Univariate analysis revealed a significant association between surgery-related strokes and surgery duration. Our retrospective findings do not necessarily mean that long surgeries can lead to surgery-related infarcts; rather, they may illustrate intraoperative surgical difficulties, such 
as those encountered in insular tumors, which are linked to stroke events.

The topics that are beyond the scope of this article and remain to be studied are methods for the prevention of strokes, including intraoperative and postoperative interventions. In addition to surgical techniques to avoid vascular complications, perioperative hemodynamic parameters, including low mean diastolic blood pressure and positive liquid balance, have been correlated with infarcts in glioma surgery. ${ }^{21,38}$ It was suggested that strict control of blood pressure and fluid balance by the anesthesiologist may assist in decreasing the risk for stroke during surgery. ${ }^{5}$ We found that low MAP at the beginning of surgery correlates with a higher rate of intraoperative strokes. Whether raising MAP by preoperative hydration can decrease the rate of stroke should be further studied.

\section{Study Limitations}

The main limitation of our study is its retrospective nature and our need to estimate and define the degree of several study parameters, including neurological deficits and KPS, based on patient records. Moreover, previous studies of high-grade glioma patients have shown various effects of intraoperative strokes on overall and progression-free survival, as compared with nonstroke patients. ${ }^{3,4,14}$ However, in the current LGG study, our $\leq 5$-year follow-up period was too short to reveal survival differences between the infarct and noninfarct groups. Finally, our study was not large enough to reveal significant differences in subgroup analyses, as in the case of speech and cognitive changes following dominant-side surgeries.

\section{Conclusions}

Patients with LGG who had undergone recurrent surgeries and especially procedures in the insula were at higher risk for intraoperative strokes. Although survival was not affected, patients with strokes sustained an impaired activity and performance status, especially during the first 3 postoperative months. Several intraoperative neurophysiological and even behavioral monitoring tools can be used as possible indicators for the impending evolution of an infarct during surgery. Particular caution should be taken in patients with relatively low blood pressure at the beginning of surgery. Further research is needed to establish guidelines for prevention and treatment protocols for intraoperative stroke.

\section{References}

1. Banks JL, Marotta CA: Outcomes validity and reliability of the modified Rankin scale: implications for stroke clinical trials: a literature review and synthesis. Stroke 38:10911096, 2007

2. Bannur U, Rajshekhar V: Post operative supplementary motor area syndrome: clinical features and outcome. Br J Neurosurg 14:204-210, 2000

3. Bette S, Barz M, Huber T, Straube C, Schmidt-Graf F, Combs $\mathrm{SE}$, et al: Retrospective analysis of radiological recurrence patterns in glioblastoma, their prognostic value and association to postoperative infarct volume. Sci Rep 8:4561, 2018

4. Bette S, Wiestler B, Kaesmacher J, Huber T, Gerhardt J, Barz $\mathrm{M}$, et al: Infarct volume after glioblastoma surgery as an independent prognostic factor. Oncotarget 7:61945-61954, 2016

5. Bette S, Wiestler B, Wiedenmann F, Kaesmacher J, Bretschneider M, Barz M, et al: Safe brain tumor resection does not depend on surgery alone-role of hemodynamics. Sci Rep 7:5585, 2017

6. Bi WL, Brown PA, Abolfotoh M, Al-Mefty O, Mukundan S Jr, Dunn IF: Utility of dynamic computed tomography angiography in the preoperative evaluation of skull base tumors. J Neurosurg 123:1-8, 2015

7. Bijker JB, Persoon S, Peelen LM, Moons KG, Kalkman CJ, Kappelle LJ, et al: Intraoperative hypotension and perioperative ischemic stroke after general surgery: a nested casecontrol study. Anesthesiology 116:658-664, 2012

8. Brown TJ, Brennan MC, Li M, Church EW, Brandmeir NJ, Rakszawski KL, et al: Association of the extent of resection with survival in glioblastoma: a systematic review and metaanalysis. JAMA Oncol 2:1460-1469, 2016

9. Chambless LB, Kistka HM, Parker SL, Hassam-Malani L, McGirt MJ, Thompson RC: The relative value of postoperative versus preoperative Karnofsky Performance Scale scores as a predictor of survival after surgical resection of glioblastoma multiforme. J Neurooncol 121:359-364, 2015

10. Chandra V, Rock AK, Opalak C, Stary JM, Sima AP, Carr M, et al: A systematic review of perioperative seizure prophylaxis during brain tumor resection: the case for a multicenter randomized clinical trial. Neurosurg Focus 43:E18, 2017

11. Dützmann S, Geßler F, Bink A, Quick J, Franz K, Seifert V, et al: Risk of ischemia in glioma surgery: comparison of first and repeat procedures. J Neurooncol 107:599-607, 2012

12. Dwolatzky T, Whitehead V, Doniger GM, Simon ES, Schweiger A, Jaffe D, et al: Validity of a novel computerized cognitive battery for mild cognitive impairment. BMC Geriatr 3:4, 2003

13. Fontaine D, Capelle L, Duffau H: Somatotopy of the supplementary motor area: evidence from correlation of the extent of surgical resection with the clinical patterns of deficit. Neurosurgery 50:297-305, 2002

14. Furuta T, Nakada M, Ueda F, Watanabe T, Arakawa Y, Higashi R, et al: Prognostic paradox: brain damage around the glioblastoma resection cavity. J Neurooncol 118:187-192, 2014

15. Gempt J, Förschler A, Buchmann N, Pape H, Ryang YM, Krieg SM, et al: Postoperative ischemic changes following resection of newly diagnosed and recurrent gliomas and their clinical relevance. J Neurosurg 118:801-808, 2013

16. Gempt J, Krieg SM, Hüttinger S, Buchmann N, Ryang YM, Shiban E, et al: Postoperative ischemic changes after glioma resection identified by diffusion-weighted magnetic resonance imaging and their association with intraoperative motor evoked potentials. J Neurosurg 119:829-836, 2013

17. Gonen T, Grossman R, Sitt R, Nossek E, Yanaki R, Cagnano E, et al: Tumor location and IDH1 mutation may predict intraoperative seizures during awake craniotomy. J Neurosurg 121:1133-1138, 2014

18. Grossman R, Nossek E, Sitt R, Hayat D, Shahar T, Barzilai O, et al: Outcome of elderly patients undergoing awake-craniotomy for tumor resection. Ann Surg Oncol 20:1722-1728, 2013

19. Hervey-Jumper SL, Berger MS: Evidence for improving outcome through extent of resection. Neurosurg Clin N Am 30:85-93, 2019

20. Hervey-Jumper SL, Berger MS: Insular glioma surgery: an evolution of thought and practice. J Neurosurg 130:9-16, 2019

21. Hervey-Jumper SL, Berger MS: Maximizing safe resection of low- and high-grade glioma. J Neurooncol 130:269-282, 2016

22. Jakola AS, Berntsen EM, Christensen P, Gulati S, Unsgård G, 
Kvistad KA, et al: Surgically acquired deficits and diffusion weighted MRI changes after glioma resection-a matched case-control study with blinded neuroradiological assessment. PLoS One 9:e101805, 2014

23. Jakola AS, Myrmel KS, Kloster R, Torp SH, Lindal S, Unsgård G, et al: Comparison of a strategy favoring early surgical resection vs a strategy favoring watchful waiting in lowgrade gliomas. JAMA 308:1881-1888, 2012

24. Joy MT, Ben Assayag E, Shabashov-Stone D, Liraz-Zaltsman S, Mazzitelli J, Arenas M, et al: CCR5 is a therapeutic target for recovery after stroke and traumatic brain injury. Cell 176:1143-1157.e13, 2019

25. Kawaguchi T, Kumabe T, Saito R, Kanamori M, Iwasaki M, Yamashita Y, et al: Practical surgical indicators to identify candidates for radical resection of insulo-opercular gliomas. J Neurosurg 121:1124-1132, 2014

26. Kim SS, McCutcheon IE, Suki D, Weinberg JS, Sawaya R, Lang FF, et al: Awake craniotomy for brain tumors near eloquent cortex: correlation of intraoperative cortical mapping with neurological outcomes in 309 consecutive patients. Neurosurgery 64:836-845, 345-346, 2009

27. Loit MP, Rheault F, Gayat E, Poisson I, Froelich S, Zhi N, et al: Hotspots of small strokes in glioma surgery: an overlooked risk? Acta Neurochir (Wien) 161:91-98, 2019

28. Lurito JT, Kareken DA, Lowe MJ, Chen SH, Mathews VP: Comparison of rhyming and word generation with FMRI. Hum Brain Mapp 10:99-106, 2000

29. Mashour GA, Sharifpour M, Freundlich RE, Tremper KK, Shanks A, Nallamothu BK, et al: Perioperative metoprolol and risk of stroke after noncardiac surgery. Anesthesiology 119:1340-1346, 2013

30. Masuda Y, Akutsu H, Ishikawa E, Matsuda M, Masumoto T, Hiyama T, et al: Evaluation of the extent of resection and detection of ischemic lesions with intraoperative MRI in glioma surgery: is intraoperative MRI superior to early postoperative MRI? J Neurosurg 131:209-216, 2018

31. McGirt MJ, Mukherjee D, Chaichana KL, Than KD, Weingart JD, Quinones-Hinojosa A: Association of surgically acquired motor and language deficits on overall survival after resection of glioblastoma multiforme. Neurosurgery 65:463-470, 2009

32. Moshel YA, Marcus JD, Parker EC, Kelly PJ: Resection of insular gliomas: the importance of lenticulostriate artery position. J Neurosurg 109:825-834, 2008

33. Neuloh G, Pechstein U, Cedzich C, Schramm J: Motor evoked potential monitoring with supratentorial surgery. Neurosurgery 54:1061-1072, 2004

34. Neuloh G, Pechstein U, Schramm J: Motor tract monitoring during insular glioma surgery. J Neurosurg 106:582-592, 2007

35. Neuloh G, Simon M, Schramm J: Stroke prevention during surgery for deep-seated gliomas. Neurophysiol Clin 37:383389,2007

36. Penfield W, Lende RA, Rasmussen T: Manipulation hemiplegia: an untoward complication in the surgery of focal epilepsy. J Neurosurg 18:760-776, 1961

37. Przybylowski CJ, Baranoski JF, So VM, Wilson J, Sanai N: Surgical morbidity of transsylvian versus transcortical approaches to insular gliomas. J Neurosurg [epub ahead of print April 5, 2019; DOI: 10.3171/2018.12.JNS183075]

38. Rey-Dios R, Cohen-Gadol AA: Technical nuances for surgery of insular gliomas: lessons learned. Neurosurg Focus 34(2):E6, 2013
39. Sanai N, Polley MY, Berger MS: Insular glioma resection: assessment of patient morbidity, survival, and tumor progression. J Neurosurg 112:1-9, 2010

40. Satoer D, Visch-Brink E, Smits M, Kloet A, Looman C, Dirven C, et al: Long-term evaluation of cognition after glioma surgery in eloquent areas. J Neurooncol 116:153-160, 2014

41. Satoer D, Vork J, Visch-Brink E, Smits M, Dirven C, Vincent A: Cognitive functioning early after surgery of gliomas in eloquent areas. J Neurosurg 117:831-838, 2012

42. Schag CC, Heinrich RL, Ganz PA: Karnofsky performance status revisited: reliability, validity, and guidelines. J Clin Oncol 2:187-193, 1984

43. Schweiger ADG, Dwolatzky T, Jaffe D, Simon ES: Reliability of a novel computerized neuropsychological battery for mild cognitive impairment. Acta Neuropsychol 1:407-413, 2003

44. Ulmer S, Braga TA, Barker FG II, Lev MH, Gonzalez RG, Henson JW: Clinical and radiographic features of peritumoral infarction following resection of glioblastoma. Neurology 67:1668-1670, 2006

45. Umemura T, Nishizawa S, Nakano Y, Saito T, Kitagawa T, Miyaoka R, et al: Intraoperative monitoring of motor-evoked potential for parenchymal brain tumor removal: an analysis of false-negative cases. J Clin Neurosci 57:105-110, 2018

46. Vlisides P, Mashour GA: Perioperative stroke. Can J Anaesth 63:193-204, 2016

47. Zelitzki R, Korn A, Arial E, Ben-Harosh C, Ram Z, Grossman R: Comparison of motor outcome in patients undergoing awake vs general anesthesia surgery for brain tumors located within or adjacent to the motor pathways. Neurosurgery 85:E470-E476, 2019

\section{Disclosures}

The authors report no conflict of interest concerning the materials or methods used in this study or the findings specified in this paper.

\section{Author Contributions}

Conception and design: Grossman, Berger. Acquisition of data: Grossman, Berger, Tzarfati, Costa, Serafimova, Korn, Vendrov, Alfasi, Krill, Aviram, Ben Moshe, Kashanian. Analysis and interpretation of data: Grossman, Berger, Tzarfati, Korn. Drafting the article: Grossman, Berger, Tzarfati, Costa, Korn, Ram. Critically revising the article: Grossman, Berger, Tzarfati, Costa, Serafimova, Korn, Vendrov, Ram. Reviewed submitted version of manuscript: Berger, Tzarfati, Costa, Serafimova, Korn, Vendrov, Alfasi, Krill, Aviram, Ben Moshe, Kashanian, Ram. Approved the final version of the manuscript on behalf of all authors: Grossman. Statistical analysis: Grossman, Berger, Tzarfati. Administrative/technical/material support: Grossman, Berger, Tzarfati. Study supervision: Grossman, Berger.

\section{Correspondence}

Rachel Grossman: Tel-Aviv Medical Center, Tel-Aviv, Israel. rachelgr@tasmc.health.gov.il. 